ECOTOX - Brazil

\title{
Avaliação da Genotoxicidade do Material Particulado na Cidade de Limeira (SP) Utilizando o Teste de Micronúcleo em Tradescantia pallida (TRAD-MCN)
}

\author{
G. T. Maziviero*, A. L. M. Ferreira, C. M. Reganhan-Coneglian, \\ A. Caloto-Oliveira, G. Almeida, A. L. Oliveira-Neto \\ Laboratório de Ecotoxicologia Aquática e Limnologia - LEAL, Faculdade de Tecnologia - FT/UNICAMP, \\ Rua Paschoal Marmo nº 1888, Jd. Nova Itália, CEP 13.484-332, Limeira, SP, Brasil
}

(Received July 3, 2009; Accepted December 14, 2010)

\begin{abstract}
RESUMO
O emprego de bioindicadores vegetais para monitoramento da contaminação atmosférica vem sendo largamente utilizado devido à fácil aplicação, manuseio e baixo custo. O presente trabalho teve como objetivo avaliar o potencial genotóxico do material particulado inalável na atmosfera da região noroeste do município de Limeira-SP, utilizando Tradescantia pallida como organismo bioindicador (Trad-MCN). Amostras de material particulado foram obtidas entre 30 de agosto a 08 de outubro de 2007 utilizando amostradores de grande volume para partículas inaláveis (AGV-MP10), no mesmo período em que as plantas foram expostas. Os resultados de quantificação indicam que os níveis estão dentro dos limites toleráveis pela legislação, porém mostram-se superiores à média anual. Os ensaios realizados apontam potencial genotóxico do material particulado, principalmente quando a frequência de micronúcleos foi mais do que o dobro do controle. Conclui-se que os contaminantes atmosféricos apresentam potencial genotóxico e que a combinação do teste de micronúcleo com T. pallida apresenta boa sensibilidade, podendo constituir uma ferramenta adicional aos estudos de monitoramento da qualidade do ar.
\end{abstract}

Palavras-chave: genotoxicidade, Tradescantia pallida, material particulado inalável $\left(\mathrm{MP}_{10}\right)$, contaminação atmosférica.

\section{ABSTRACT \\ Assessment of particulate matter genotoxicity at Limeira city (SP) using the micronucleus assay in Tradescantia pallida (TRAD-MCN)}

The use of plants for air contamination biomonitoring has been increased due to the low costs and the easy application and handling. Thus, this study aimed to evaluate the genotoxic potential of inhalable particulate matter in the atmosphere of Limeira city (SP, Brazil) by assessing micronucleus (Trad-MCN) in Tradescantia pallida. Samples were collected from august $30^{\text {th }}$ to October $8^{\text {th }}, 2007$ using large volume samplers (HI-VOL-PM10). The results indicated that particulate matter levels are within the tolerable limits defined by the legislation. However, they were higher than the annual average values. A genotoxic potential of the particulate matter was seen in some cases where micronucleus frequency more than double in relation to the control. As conclusion, Limeira air contaminants are potentially genotoxic, and the combination of micronucleuos assay and T. pallida showed a good sensibility, and can be used in further studies as a tool of air quality monitoring.

Keywords: genotoxicity, Tradescantia pallida, particulate matter $\left(\mathrm{PM}_{10}\right)$, atmosphere pollution.

* Corresponding author: Guilherme Thiago Maziviero, e-mail: gmaziviero@yahoo.com.br 


\section{INTRODUÇÃO}

O acelerado desenvolvimento industrial e urbano, impulsionado pela revolução industrial desde meados do século XIX, tem resultado em elevada tendência na emissão de agentes tóxicos na atmosfera. Tais alterações podem ser observadas em escala global, com impactos significativos na atmosfera, como o aumento de gases do efeito estufa, redução da camada de ozônio, chuva ácida, entre outros (Philippi, 2005).

Atualmente a determinação sistemática da qualidade do ar se justifica pela importância na manutenção da qualidade de vida tanto nos dias de hoje quanto para gerações futuras (Torres \& Martins, 2005). Dessa forma, a presença de agentes potenciais de poluição atmosférica nos espaços urbanos, que ameaçam a saúde e a qualidade de vida dos organismos, assim como a integridade do meio abiótico, tem levado os cientistas a buscar medidas e estratégias destinadas à detecção precoce de processos poluidores, assim como de instrumentos e métodos de intervenção em áreas com exposição humana a contaminantes (Carneiro, 2004).

O monitoramento ambiental pode ser realizado por análises químicas, de forma a detectar a concentração dos contaminantes, fornecendo informações quantitativas relevantes sobre a composição da atmosfera. No entanto, os efeitos sobre determinados vegetais e animais, medidos por bioindicadores ou indicadores naturais da qualidade do ambiente, podem ser utilizados para a avaliação qualitativa da contaminação atmosférica. Esta abordagem metodológica denomina-se monitoramento biológico ou simplesmente biomonitoramento (Luiz et al, 2005). O uso de bioindicadores pode levar a identificação dos efeitos diretos sobre os organismos sejam eles expressos na morfologia, comportamento ou até mesmo no DNA, sob forma de efeitos genotóxicos e/ou mutagênicos (Silva, 2005).

As plantas têm se mostrado úteis para monitorar a qualidade do ar, já que apresentam fáceis manuseio, cultivo e cuidados, com custos relativamente baixos, relação aos demais testes in vivo, mostrando respostas conservativas e de fácil avaliação (Luiz et al, 2005). Entre essas, a Tradescantia pallida encontrada com facilidade em canteiros e jardins, é uma espécie tetraplóide, extremamente resistente a parasitas e insetos, que brota e cresce facilmente, florescendo o ano inteiro (Carvalho, 2005).

O teste de micronúcleo em Tradescantia pallida (TRAD$\mathrm{MCN}$ ) oferece as vantagens de um procedimento simples e eficaz, e permite a avaliação do dano cromossômico em preparação citológica de rápida execução. $\mathrm{O}$ custo financeiro e facilidade de acesso ao material de estudo são fatores adicionais às outras vantagens dessa metodologia. Além disso, em divisão meiótica, os cromossomos são mais sensíveis à quebra do que os cromossomos mitóticos, especialmente na prófase I, durante o paquíteno e o diplóteno, fato este, que aumenta a sensibilidade e, portanto, a eficiência do teste (Silva, 2005).

A avaliação das alterações genéticas de T. pallida pode ser realizada através da detecção de mutações induzidas por contaminantes presentes no ar, no solo ou na água, que promovam aberrações cromossômicas de ordem clastogênica (quebra dos cromossomos). Os dados obtidos em experimentos com TRAD-MCN são, consistentes, precisos e confiáveis, até mesmo em resposta a baixos níveis de radiação ( $<5$ cGy) e mutágenos químicos, que raramente é obtida em outros ensaios biológicos (Ma, 1979; Carvalho, 2005). Sendo assim, esta metodologia é aplicável ao monitoramento in situ para a avaliação de contaminação atmosférica, ou sob condições de laboratório (ex situ) (Rodrigues et al, 1997 ).

De acordo com o Relatório de Qualidade do Ar do Estado de São Paulo, publicado em 2006, pela Companhia de Tecnologia de Saneamento Ambiental (CETESB, 2006), os municípios de Limeira e Santa Gertrudes apresentam os maiores níveis de material particulado inalável $\left(\mathrm{MP}_{10}\right)$ do interior do estado, ultrapassando o Padrão de Qualidade do Ar estabelecido pelo CONAMA (1990). O mesmo relatório ainda aponta que esta problemática também se fez presente nos anos anteriores.

\section{MATERIAL E MÉTODOS}

Material Particulado - A amostragem do material particulado inalável foi realizada a noroeste do município de Limeira, latitude $\mathrm{S} 22^{\circ} 36^{\prime}$ e longitude $\mathrm{W} 47^{\circ} 25^{\prime}$ e altitude $641 \mathrm{~m}$ (Google Earth, 2007), localizado a 154 km de São Paulo. Para a coleta utilizou-se um amostrador de grande volume para partículas inaláveis (AGV-MP10), da marca ENERGÉTICA ${ }^{\circledR}$ com cabeça TISCH ENVIRONMENTAL ${ }^{\circledR}$, devidamente calibrado conforme as recomendações da ABNT - NBR 13412 (ABNT, 2005). Foram realizadas quatro amostragens, em período de 24 horas ininterruptas, respeitando-se o intervalo de duas semanas entre as coletas no período de agosto a outubro de 2007.

Bioensaio de genotoxicidade - As plantas geneticamente homogêneas foram cedidas pelo Instituto Nacional de Pesquisas Espaciais (INPE), e a intoxicação do organismo-teste deu-se através de solução do material particulado em água destilada, submetendo o filtro da coleta à agitação mecânica em mesa vibratória de freqüência variável. As hastes com inflorescências de T. pallida foram expostas às soluções por um período de 8 horas, seguido de 24 horas de recuperação em solução Hoagland com aeração. Após fixadas em Carnoy por 48 horas, as lâminas foram preparadas para visualização das tétrades e contagem de micronúcleos (Figura 1), conforme Ma (1981). A visualização das células foi realizada em microscópio óptico, sob magnitude de 400 vezes, onde foram contadas aleatoriamente 300 tétrades por lâmina com a quantificação dos micronúcleos.

\section{RESULTADOS E DISCUSSÃO}

Os índices de umidade relativa do ar, durante os dias de amostragem foram: $68,5,46,5,64$ e $51,5 \%$ para os dias 30 de agosto, 12 de setembro, 27 de setembro e 08 de outubro, respectivamente. De maneira geral, é possível constatar relação inversamente proporcional entre umidade relativa e concentração de material particulado em suspensão atmosférica. No entanto, de acordo com a Figura 2 não foi possível constatar tal relação, uma vez que o dia de maior concentração de material particulado $\left(100,0 \mu \mathrm{g} \cdot \mathrm{m}^{-3} \mathrm{em} 27 / 09\right)$ não apresentou a menor taxa de umidade relativa (64\%). Dessa forma, a maior concentração pode estar diretamente relacionada à atividade antrópica, como a queima de palha de cana, intensa circulação de veículos, atividades de 
mineração ou ainda, com mudanças do clima como direção e velocidade dos ventos e pressão atmosférica.

Em todas as amostragens, a concentração do material particulado presente na atmosfera de Limeira ultrapassa o limite da média aritmética anual (M.A.A.) de qualidade do ar (exposição a longo prazo, $50 \mu \mathrm{g} . \mathrm{m}^{-3}$ ), previsto pelo CONAMA (1990) (Figura 2). Porém, não atinge o limite para o período de 24 horas (exposição a curto prazo, $150 \mu \mathrm{g} . \mathrm{m}^{-3}$ ), enquadrando-se, portanto, aos limites toleráveis pela legislação neste intervalo de tempo. Todavia, o Relatório de Qualidade do Ar no Estado de São Paulo, publicado pela CETESB (2006), indica que o município de Limeira em 2006 ultrapassou o padrão anual de qualidade do ar em material particulado inalável, atingindo a marca de $52 \mu \mathrm{g} . \mathrm{m}^{-3}$. Já o relatório de 2007 aponta que este comportamento vem se mantendo nos últimos anos, e destaca ainda que o município de Limeira foi o único na Unidade de Gerenciamento de Recursos Hídricos (UGRHI - 5), a qual integra, que apresentou níveis acima da MAA (CETESB, 2007). Tal fato corrobora com os dados apresentados, mesmo que em um curto intervalo de tempo.

Quanto ao ensaio de TRAD-MCN, a freqüência de micronúcleos do controle negativo se mostra relativamente alta (Tabela 1), fato que pode ser explicado devido a impurezas

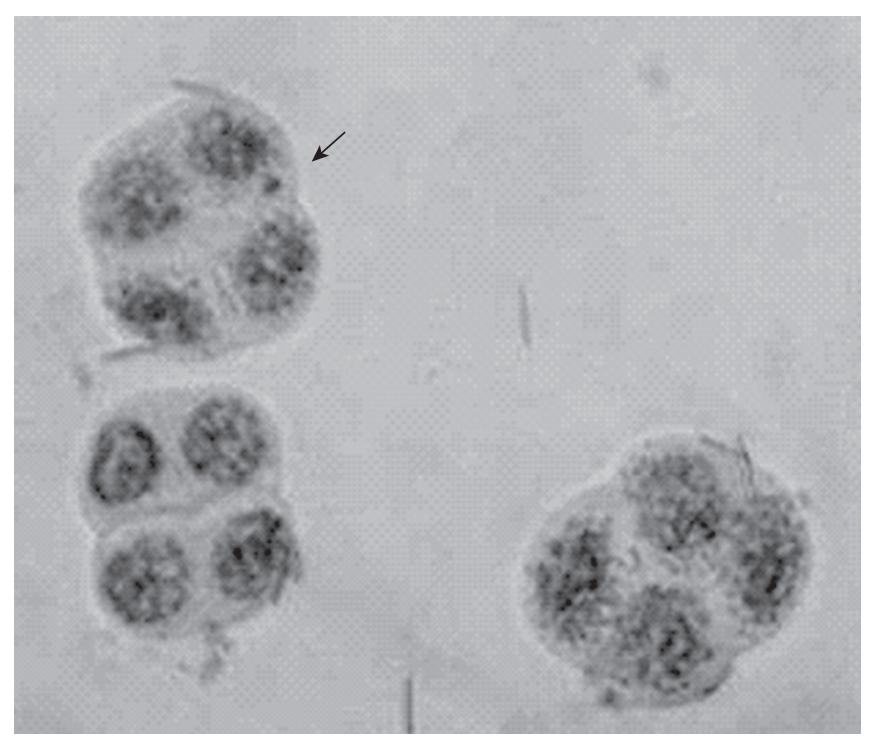

Figura 1 - Tétrades de grão de pólen, com e sem micronúcleo (magnificação 400x). presentes no filtro de amostragem, no qual o fabricante destaca a possibilidade de existirem substâncias residuais como $\mathrm{Fe}, \mathrm{Ni}$, $\mathrm{Mn}, \mathrm{Cr}, \mathrm{Pb}, \mathrm{Zn}, \mathrm{Cd}$ e Cu. Zagatto \& Bertoletti (2006) afirmam que as mutações são a fonte de variabilidade genética de uma população, sendo, portanto, fundamentais para a manutenção das espécies. A presença de micronúcleos também se dá por um processo natural durante a divisão celular, uma vez que essa taxa é controlada pelo mecanismo de reparo celular (Rodrigues, 1999). O controle negativo garante maior representatividade estatística, uma vez que se pretende avaliar a toxicidade do $\mathrm{MP}_{10}$, desconsiderando, portanto a taxa basal.

Avaliando as freqüências de micronúcleos, observa-se aumento significativo em relação ao controle (Tabela 1), indicando que, mesmo em baixas concentrações de contaminantes, é possível avaliar o potencial genotóxico do material particulado inalável através do ensaio de micronúcleo. Isso corrobora com os resultados de Solenská et al. (2006), Batalha et al. (1999) e Guimarães et al. (2000). Apesar de comprovado o efeito genotóxico nos organismos-teste, existe, todavia, grandes diferenças organizacionais e fisiológicas entre vegetais superiores e mamíferos, principalmente no metabolismo, que podem levar a diferentes reações frente a uma lesão cromossômica. No ser humano, por exemplo, apenas uma fração mínima da lesão sobre o DNA pode ou não levar a mutações, ao passo que na T. pallida a grande maioria das lesões resulta em mutação por conta dos diferentes mecanismos de reparo celular (Carvalho,

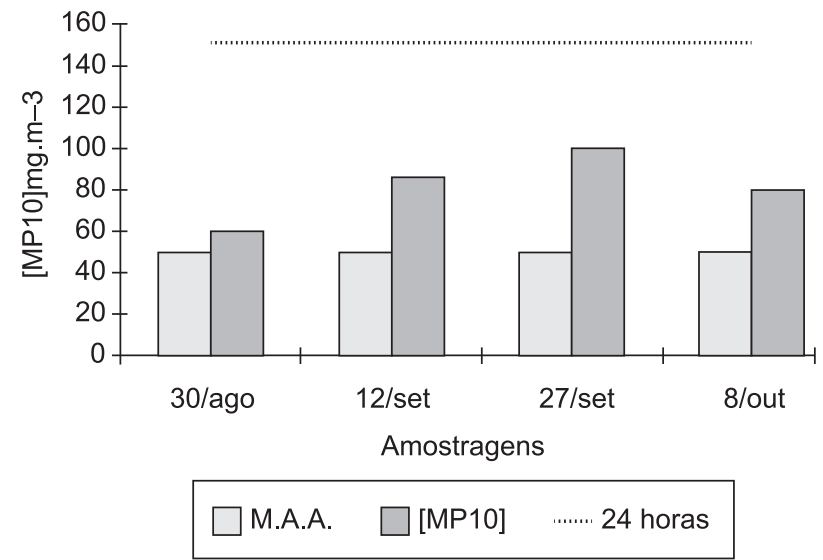

Figura 2 - Concentração de material particulado inalável $\left(\mathrm{MP}_{10}\right)$ na atmosfera de Limeira comparado com a Média Aritmética Anual (M.A.A.) e o limite máximo permitido a curto prazo ( 24 horas).

Tabela 1 - Contagem do número de micronúcleos por tétrade para o controle negativo e amostra 12 de setembro de 2007.

\begin{tabular}{|c|c|c|c|c|c|c|c|c|c|c|c|c|}
\hline \multirow[t]{2}{*}{ Lâmina } & \multicolumn{6}{|c|}{ Controle Negativo $\left(\mathrm{H}_{2} \mathrm{O}\right)$} & \multicolumn{6}{|c|}{ Amostra 12 de setembro $\left(131 \mathrm{mg} \cdot \mathrm{L}^{-1}\right)^{\star}$} \\
\hline & $\mathbf{0}$ & 1 & 2 & 3 & $\mathrm{X} / 300$ & $\%$ & $\mathbf{0}$ & 1 & 2 & 3 & $\mathrm{X} / 300$ & $\%$ \\
\hline 1 & 286 & 6 & 4 & 0 & $14 / 300$ & 4,67 & 271 & 17 & 3 & 2 & $29 / 300$ & 9,67 \\
\hline 2 & 281 & 10 & 3 & 1 & $19 / 300$ & 6,34 & 279 & 19 & 1 & 0 & $21 / 300$ & 7,00 \\
\hline 3 & 289 & 9 & 1 & 0 & $11 / 300$ & 3,67 & 281 & 13 & 3 & 0 & $19 / 300$ & 6,34 \\
\hline 4 & 289 & 7 & 2 & 0 & $11 / 300$ & 3,67 & 281 & 11 & 4 & 0 & $19 / 300$ & 6,34 \\
\hline 5 & 288 & 10 & 1 & 0 & $12 / 300$ & 4,00 & 269 & 18 & 5 & 3 & $31 / 300$ & 10,34 \\
\hline 6 & 287 & 7 & 0 & 2 & $13 / 300$ & 4,34 & 276 & 14 & 5 & 0 & $24 / 300$ & 8,00 \\
\hline
\end{tabular}

* 131 mg.L-1 corresponde à concentração da solução de intoxicação (solubilização do material particulado em água destilada). 
2005). Um determinado aumento na freqüência do dano inicial elevará, na mesma proporção, a taxa de incidência de mutações, tanto na T. pallida quanto no ser humano.

De acordo com os resultados apresentados é possível concluir que as concentrações de material particulado inalável no município de Limeira, apesar de dentro dos limites diários, podem ultrapassar as médias anuais do padrão exigido pelo CONAMA(1990). O ensaio de genotoxicidade com TRAD-MCN em T. pallida apresentou sensibilidade ao agente de exposição e pode ser empregado, após experimentos de padronização, como mais uma ferramenta nos estudos de monitoramento ambiental. Mesmo em baixas concentrações, os contaminantes apresentam características genotóxicas, sendo sugerido estudo mais aprofundado sobre o tema.

\section{REFERÊNCIAS}

ABNT, Associação Brasileira de Normas Técnicas, 2005, $N B R$ 13412, Material particulado em suspensão na atmosfera - Determinação da concentração de partículas inaláveis pelo método do amostrados de grande volume acoplado a um separador inercial de partículas. Rio de Janeiro, RJ. 08 p.

BATALHA, J. R. F., GUIMARÃES, E. T., LOBO, D. J. A., LICHTENFELS, A. J. F. C., DEUR, T., CARVALHO, H. A., ALVES, E. S., DOMINGOS, M., RODRIGUES, G. S. \& SALDIVA, P. H. N., 1999, Exploring the clastogenic effects of air pollutants in São Paulo (Brazil) using the Tradescantia micronuclei assay. Mutat. Res. 426:229-232. doi:10.1016/S00275107(99)00073-1

CARNEIRO, R. M. A., 2004, Bioindicadores vegetais de poluição atmosférica: uma contribuição para a saúde da comunidade. Dissertação (Mestrado em Enfermagem)-USP, Ribeirão Preto, $169 \mathrm{p}$.

CARVALHO, H. A. A., 2005, Tradescantia como bioindicador vegetal na monitoração dos efeitos clastogênicos das radiações ionizantes. Radiol Bras. SP. 38(6).

CETESB, Companhia de Tecnologia de Saneamento Ambiental, 2007, Relatório de qualidade do ar no estado de São Paulo 2006. São Paulo, SP, 167 p.

CONAMA, Conselho Nacional do Meio Ambiente, 1990, Resolução CONAMA $n^{\circ} 03$ de 28.06.1990. Padrões da Qualidade do Ar. Brasília, DF.

GOOGLE Earth - sOFTWARE. Available from: <http://www. google.com.br>. Access in: 2007.
GUIMARÃES, E. T., DOMINGOS, M., ALVES, E. S.; CALDINI, N., LOBO, D. J., LICHTENFELS, A. J. \& SALDIVA, P. H., 2000, Detection of the genotoxicity of air pollutants in and around the city of São Paulo (Brazil) with the Tradescantiamicronucleus (Trad-MCN) assay. Environ. Exp. Bot. 44:1-8. doi:10.1016/S0098-8472(00)00050-2.

LUIZ, E. J., LAVENDOWSKI, I. M. F., OLIVEIRA, G. P., GUIMARÃES, E. T., DOMINGOS, M., SALDIVA, P. H. N., 2005, Sentindo a cidade: biomonitoramento da qualidade do ar de Santo André com plantas da espécie Tradescantia pallida e a Educação Ambiental.

MA, T. H., 1979, Micronuclei induced by X-Rays and chemical mutagens in meiotic pollen mother cells of Tradescantia - a promising mutagen system. Mutat. Res., 64:307-313. doi:10.1016/0165-1161(79)90123-7.

MA, T. H., 1981, Tradescantia Micronucleus bioassay and pollen tube chromatid aberration test for in situ monitoring and mutagen screening. Environ. Health Perspect. 37:85-90.

PHILIPPI Jr, A., 2005, Saneamento, saúde e ambiente: fundamentos pra um desenvolvimento sustentável. Manole, Barueri.

RODRIGUES, G. S., 1999, Bioensaios de toxicidade genética com plantas superiores Tradescantia (MCN e SHM), milho e soja. Embrapa Meio Ambiente, Jaguariúna, São Paulo.

RODRIGUES, G. S., MA, T. H., PIMENTEL, D. \& WEINSTEIN, L. H., 1997, Tradescantia Bioassays as monitoring systems for environmental mutagenesis: a review. Crit. Rev. Sci., 16:325-359.

SILVA, J. S., 2005, Efeitos genotóxicos em tétrades de Tradescantia pallida (Rose) D.R. Hunt var. purpurea Induzidos por poluentes atmosféricos na cidade do Salvador-BA. Monografia (Bacharelado em Ciências Biológicas)-Universidade Estadual de Feira de Santana, Bahia.

SOLENSKÁ, M., MICIETA, K. \& MISIK, M., 2006, Plant bioassays for an in situ monitoring of air near an industrial area and a municipal solid waste-Zilina (Slovakia). Environ. Monit. Assess., 115:499-508. doi: 10.1007/s10661-006-7240-2.

TORRES, F. T. P. \& MARTINS, L. A., 2005, Fatores que influenciam na concentração do material particulado inalável na cidade de Juiz de Fora (MG). Caminhos de Geografia, Minas Gerais.

ZAGATTO, P. A. \& BERTOLETTI, E., 2006, Ecotoxicologia aquática - princípios e aplicações. RiMa, São Carlos. 